\title{
pro.posições
}

$e$-ISSN 1980-6248

DOSSIÊ: Homeschooling e o Direito à Educação

\section{Homeschooling: entre dois jusnaturalismos?}

\section{Homeschooling: between two jusnaturalisms?}

Carlos Roberto Jamil Cury (i)

(i) Pontifícia Universidade Católica de Minas Gerais, Belo Horizonte, MG, Brasil.

crjcury.bh@terra.com.br

Resumo: Este artigo pretende tomar como alvo a tensão existente entre o direito à educação e o dever da família de colocar as crianças na escola. Essa tensão, no caso do movimento intitulado homeschooling, toma partido do direito e, neste sentido, questiona a obrigatoriedade. Dado o caráter genérico de determinadas Declarações Internacionais das quais o Brasil é signatário, há famílias pleiteando a possibilidade de educação escolar doméstica. Para tanto, podem-se buscar dois fundamentos do movimento. Uma vertente do movimento se apoia tanto na liberdade de ensino, quanto no direito da família pelo qual cabe a ela escolher que tipo de escola quer para seus filhos e que tipo de educação quer para eles. Procura cumprir, suo modo, a obrigatoriedade escolar em casa, já que se trata de um mandamento legal. Outra se apoia na liberdade de ensino, contestando a obrigatoriedade nos termos legais estabelecidos pelo Estado. Ao colocar o direito da família ou a liberdade como prévios a qualquer obrigação advinda do Estado, este movimento parece retomar, como fundamento de sua argumentação, ao menos de modo amplo, a tese ou as teses do jusnaturalismo, seja ele pela vertente medieval, ou pela moderna. Justificar as razões dessa obrigatoriedade e insistir na importância do ensino obrigatório na faixa etária prevista em lei, com a devida presença dos alunos em instituições próprias de ensino presencial, é próprio do dever do Estado. É dessa tensão que este artigo se ocupa.

Palavras-chave: Homeschooling, obrigatoriedade escolar, educação escolar e dever do Estado, direito à educação 


\section{pro.posıções}

Abstract: This essay aims to fix two fundamentals of the mouvement named as homeschooling. This mouvement, in its two versions, is supported both by the family right and by freedom of teaching. By the first, the argument is that it's up to the family to choose what kind of school and what kind of teaching is whorthwhile for their children. Family tries to fulfill at home, suo modo, the legal requirement, since education is a state legal commandment. On the other hand, some of the families desiring homeschooling contest the legal obligation as it is stablished by the State. By placing the family right or the freedom of teaching as prior to any obligation coming from the State, this mouvement seems to widely resume the arguments of jusnaturalism in its medieval, and even modern features. Also due to the generic character of some international declarations of which Brazil is subscriber, there are families arguing in favor of homeschooling. This essay stresses the importance of teaching obligation as an inalienable task of the State of Right to face the request of bomeschooling.

Keywords: homeschooling, freedom of teaching, obligation, duty of the state

\section{Introdução}

Este artigo pretende estabelecer, mediante uma provocação teórica, dois fundamentos do movimento intitulado homeschooling, o qual questiona a obrigatoriedade da educação escolar disposta na legislação nacional.

Este estudo se junge a uma produção já existente sobre o assunto como Barbosa (2013), Boudens (2001, 2002) Chartier (2013), Cury (2006, 2009, 2013) e Vasconcelos (2004). Esta produção, ínsita no campo do direito à educação que tem como um de seus focos a obrigatoriedade escolar, toma a si tal temática, dado que o questionamento dos propugnadores da homeschooling incide justamente sobre este dever do Estado. Ademais, esse questionamento tem sido encaminhado para instâncias como Conselhos de Educação e Tribunais, argumentando com Tratados Internacionais e com a experiência de educação doméstica autorizada em vários países. Entrementes, o recorte aqui proposto busca analisar os fundamentos da defesa da não obrigatoriedade, tendo por detrás, como sua base, os princípios do jusnaturalismo.

O movimento que se organiza em torno da denominada homeschooling, em suas mais distintas versões, se apoia, de um lado, no direito da família, e, de outro, na liberdade de ensino. Em ambos os casos, a família está implicada. Importa ver como acontece tal implicação nas vertentes do jusnaturalismo. 


\section{pro.posições}

$e$-ISSN 1980-6248

De modo geral, o argumento básico dos propugnadores alega que, pelo direito de família, cabe a ela não só escolher que tipo de escola quer para seus filhos como também e, sobretudo, que tipo de educação quer para eles.

Este movimento assinala que esse constrangimento legal não precisa se dar nas instituições escolares constituídas para tal, mediante legislação. Pode haver instrução, inclusive respeitando padrões curriculares, sem que ela ocorra em estabelecimentos escolares.

É neste sentido que ele busca cumprir, suo modo, a obrigatoriedade escolar, já que se trata de um mandamento legal. Mas, ao argumento anterior, o movimento também se apoia na liberdade de ensino pela qual há a contestação de que tal obrigatoriedade seja cumprida nos termos estabelecidos pelo Estado e na legislação que rege a educação escolar. Não se pode deixar de assinalar que o movimento da homeschooling trabalha em uma dupla tensão entre direito e dever. Se a educação escolar é um direito - interroga-se ele - e assim uma prerrogativa do sujeito em agir ou não agir conforme sua titularidade e sua liberdade, como combiná-la com a obrigatoriedade do mesmo sujeito, dispositivo que se impõe por um constrangimento legal e, portanto, como um dever?

Antes de entrar no argumento da homeschooling, cumpre trazer à tona um pequeno histórico de como essa questão já foi tratada na legislação brasileira.

\section{Esboço histórico}

A educação escolar no Brasil nem sempre se pautou pela exclusividade da instituição escolar como locus da proteção intelectual. Até a Constituição de 1988, havia a possibilidade de que a instrução primária pudesse ser dada no lar, dispositivo que comparecia na legislação infraconstitucional (Cury, 2006, 2013).

Apenas alguns exemplos a esse respeito.

A Constituição de 1946 (Constituição BR, 1946), no capítulo de educação, dispõe, no art. 166, que "a educação é direito de todos e será dada no lar e na escola". Também a lei n. 4.024/61(Lei BR, 1961), a das diretrizes e bases da educação nacional, reproduz, no seu art. 2o, o disposto na Constituição e, no art.30, proíbe o exercício de funções públicas dos pais 


\section{pro.posıções}

$e$-ISSN 1980-6248

que não tenham feito prova de matrícula de seus filhos em escolas "ou de que lhe está sendo ministrada educação no lar"'.

A presente positivação jurídico-legal, posta no art. 208 da Constituição (Constituição BR, 1988), \3o combinado com o \10; no art. 55 do Estatuto da Criança e do Adolescente (Lei BR, 1990) e no art. 6o da Lei de Diretrizes e Bases da Educação Nacional (Lei BR, 1996) não mais se refere ao lar ou família como loci desta obrigatoriedade. Com efeito, observe-se na respectiva sequência:

Art. 208 - O dever do Estado com a educação será efetivado mediante a garantia de:

\3o: Compete ao poder público recensear os educandos no ensino fundamental, fazer-lhes a chamada e zelar, junto aos pais ou responsáveis, pela frequência à escola.

Ao combinar este parágrafo da frequência à escola com o $\int 10$ : “o acesso ao ensino obrigatório e gratuito é direito público subjetivo", nos termos da Emenda Constitucional n. 59/2009 (Emenda Constitucional BR, 2009), vê-se que a obrigatoriedade e a gratuidade foram estendidas para a faixa etária dos quatro (4) aos dezessete (17) anos. Leia-se o novo inciso I do art. 208: "educação básica obrigatória e gratuita dos 4 (quatro) aos 17 (dezessete) anos de idade, assegurada inclusive sua oferta gratuita para todos os que a ela não tiveram acesso na idade própria" (Constituição BR, 1988).

Ou seja: tudo indica que os termos do $\$ 3$ o do art. 208 devem ser lidos à luz do inciso I do mesmo artigo. Isto é, ampliou-se tanto o dever do Estado, inclusive quanto ao recenseamento e chamada, como o princípio do direito público subjetivo junto com a obrigatoriedade.

Já o Estatuto da Criança e do Adolescente, lei n. 8.069/90 (Lei BR, 1990), dispõe de modo direto: “Art. 55 - Os pais ou responsável têm a obrigação de matricular seus filhos ou pupilos na rede regular de ensino".

E a atual redação das Diretrizes e Bases da Educação Nacional, lei n. 9.394/96 (Lei BR, 1995), também ordena: “Art. 6o. - É dever dos pais ou responsáveis efetuar a matrícula das crianças na educação básica a partir dos 4 (quatro) anos de idade ". 2

\footnotetext{
${ }^{1}$ Pupilo é aquela criança impúbere que não está submetida ao poder conjugal, por ser órfão ou submetido à tutela. Em sentido geral, pupilo é uma criança ou adolescente órfão sob tutela.
} 


\section{pro.posições}

É possível ainda aduzir o Código Penal (Decreto-Lei BR, 1940) que, no Capítulo Dos crimes contra a assistência familiar, erige como crime de abandono intelectual: "Art. 246 deixar, sem justa causa, de prover à instrução primária de filho em idade escolar ".3

Além disso, a Declaração Universal dos Direitos do Homem da Organização das Nações Unidas, de 1948, da qual o Brasil é signatário, diz em seu artigo 26, \ $3^{\circ}$ : "os pais têm prioridade de direito na escolha do gênero de instrução que será ministrada a seus filhos".

O lar pode ser assumido como um gênero de instrução, dado que este termo tem uma longa tradição de elo com a escola?

À vista deste novo desenho do ordenamento jurídico, a tensão entre direito e dever tornou-se mais explícita por conta do movimento da homeschooling. Diferentemente de outras constituições e leis, o atual ordenamento dispõe de modo claro sobre a obrigatoriedade dos sujeitos em idade escolar (4 a 17 anos) à educação escolar, como visto anteriormente (Horta, 2013). Mas isso não quer dizer que a tensão tenha deixado de existir. ${ }^{4}$

\section{A obrigatoriedade}

A tensão entre direito e dever foi retomada pelo mesmo Bobbio (1995) para quem: "Em geral, qualquer extensão da esfera pública por razões igualitárias, na medida em que precisa ser imposta, restringe a liberdade de escolha na esfera privada, que é intrinsecamente inigualitária” (p. 113).

Tal restrição à liberdade é assim justificada por este autor na mesma obra:

\footnotetext{
${ }^{2}$ A redação original previa: "é dever dos pais ou responsáveis efetuar a matrícula dos menores, a partir dos sete anos de idade". Posteriormente a lei n. 11.114/2005 abaixou a idade de entrada para seis anos.

${ }^{3}$ Abandono vem, proximamente, do francês a ban donner e que significa deixar ir para o exílio. Bannjan no frâncico significa exílio. Abandono, pois, tem a ver com uma espécie de banimento. Mais remotamente, vem de uma locução germânica a bandon que quer dizer: deixar à mercê de. Contrariamente à assistência, própria do art. $227 \mathrm{da}$ Constituição, trata-se de um estado de desamparo. Como este dispositivo vigorou quando ainda era legal a educação no lar, parece-me que não se poderia falar em crime quando se pratica esta desobediência civil. Há que haver uma categoria específica para o descumprimento deste estatuto legal.

4 Há vários aspectos de ordem prática envoltos na proposta deste movimento, como competência dos pais/tutores em relação à sua formação profissional no âmbito da pedagogia ou da licenciatura, o papel do Estado no controle relativo à certificação, entre outros.
} 


\section{pro.posıções}

$e$-ISSN 1980-6248

O mesmo princípio fundamental daquela forma de igualitarismo mínimo própria da doutrina liberal, segundo a qual todos os homens têm direito à idêntica liberdade, salvo exceções a serem justificadas, implica que cada um limite a própria liberdade para torná-la compatível com a liberdade de todos os outros, de modo a não impedir que os outros também usufruam da sua mesma liberdade. (p.114)

Em outro ângulo de sua análise, Bobbio (1987) deixa claro um dos sentidos que presidiu a imposição da obrigatoriedade escolar:

Esta tentativa de escolher as reformas que são ao mesmo tempo liberadoras e igualitárias deriva da constatação de que há reformas liberadoras que não são igualitárias, como seria o caso de qualquer reforma de tipo neoliberal, que oferece ampla margem de manobra aos empresários para se desvencilharem dos vínculos que advêm da existência de sindicatos e comitês de empresa, ao mesmo tempo em que se destina a aumentar a distância entre ricos e pobres; por outro lado, existem reformas igualitárias que não são liberadoras, como toda a reforma que introduz uma obrigação escolar, forçando todas as crianças a ir à escola, colocando a todos, ricos e pobres, no mesmo plano, mas por meio de uma diminuição da liberdade. (p. 23)

Essa análise de Bobbio se aproxima daquela levada a cabo por Marshall (1967) para quem a educação, sendo um pré-requisito necessário da liberdade civil, é imanente à cidadania e se torna necessária para o exercício de outros direitos próprios da vida cidadã, em especial os ligados aos direitos sociais. O poder público, nesse caso, intervém no sistema contratual de mercado, já que, segundo ele, o exercício do conjunto de direitos deve ser utilizado por pessoas conscientes, para o que a alfabetização e o letramento são indispensáveis. Segundo Marshall (1967),

a educação das crianças está diretamente relacionada com a cidadania, e, quando o Estado garante que todas as crianças serão educadas, este tem em mente, sem sombra de dúvida, as exigências e a natureza da cidadania. Está tentando estimular o desenvolvimento de cidadãos em formação. O direito à educação é um direito social de cidadania genuíno porque o objetivo da educação durante a infância é moldar o adulto em perspectiva. Basicamente, deveria ser considerado não como o direito da criança frequentar a escola, mas como o direito do cidadão adulto ter sido educado. (p. 73)

Comentando o pensamento do economista liberal neoclássico Alfred Marshall, para quem a pessoa ignorante perde as condições reais de apreciar e escolher livremente as coisas, Marshall (1967) converge:

o Estado teria de fazer algum uso de sua força de coerção, caso seus ideais devessem ser realizados. Deve obrigar as crianças a frequentarem a escola porque o ignorante não pode 


\section{pro.posıções}

$e$-ISSN 1980-6248

apreciar e, portanto, escolher livremente as boas coisas que diferenciam a vida de cavalheiros daquela das classes operárias. (p. 60)

Ele reconheceu somente um direito incontestável, o direito de as crianças serem educadas, e neste único caso ele aprovou o uso de poderes coercivos pelo Estado. (p. 63)

Essa convergência de pensamento, justificando a educação primária pública como obrigatória e gratuita, pode-se vê-la neste trecho de Marshall (1967):

No período inicial da educação pública na Inglaterra, os direitos eram mínimos e iguais. Mas, como já observamos, ao direito veio corresponder uma obrigação, não apenas porque o cidadão tenha uma obrigação para consigo mesmo, assim como um direito de desenvolver o que se encontra latente dentro de si - um dever que nem a criança, nem o pai podem apreciar em toda a sua extensão - mas porque a sociedade reconheceu que ela necessitava de uma população educada. (p. 99)

Desse modo, a fim de que o cidadão pudesse participar de modo mais igual da vida social e com isso ampliar seu espectro de liberdade diante da tomada de decisões, era preciso que ele contivesse em si o desenvolvimento de sua marca registrada: a razão. A propriedade de si se expressa na efetivação da razão. Seria, pois, preciso desenvolvê-la e estimulá-la, no mínimo combatendo a ignorância. Assim, a educação primária é vista como uma atividade pertencente ao interesse geral. Logo, o desencadeamento do potencial da razão, que cada um traz consigo e que amplia a capacidade de escolha, não poderia ser nem objeto de uma ação assistemática e nem produto de um acaso bem-sucedido.

Desse modo, o Estado, como ente de razão e assegurador das condições para a liberdade e arbítrio do cidadão, torna a educação escolar obrigatória. E é isso que será contestado pelo movimento da homeschooling.

\section{A homeschooling e as teses do jusnaturalismo}

Ao colocar o direito da família e/ou a liberdade como prévios a qualquer obrigação institucionalizada advinda do Estado, o movimento parece retomar, como fundamento de sua argumentação, ao menos de modo amplo, a tese ou as teses do jusnaturalismo, seja ele pela vertente medieval, seja pela moderna. 


\section{pro.posıções}

De modo geral, o jusnaturalismo ou direito natural, como o próprio nome o diz, significa um direito que decorre da natureza como seu fundamento. Como afirma Gratien (1993),

pode-se provar que uma norma positiva (ou então uma norma que se quer tornar positiva), é justa, unicamente graças a uma demonstração a partir de princípios universalmente válidos, cujo caráter obrigatório é autoevidente. Os princípios são evidentes porque eles decorrem da natureza que, por definição, é o que é e não pode ser objeto de uma escolha, de uma tomada de posição avaliativa e nem o produto da vontade e das ações dos homens. ${ }^{5}$ (p.200, tradução nossa)

Reitere-se que, ao tornar o ensino escolar obrigatório para todos, o movimento da homeschooling entende que o Estado não deve impor forçosamente que ele se dê em instituições escolares. A realização dessa obrigação e desse dever encontra nas instituições escolares próprias uma opção legítima e historicamente mais ampla. Mas, segundo este movimento, esta constituição de conhecimentos deve estar aberta para que sua oferta possa ocorrer também em cursos virtuais, em outros espaços adequados e mesmo no lar.

O movimento da homeschooling vai contestar, não propriamente, as possibilidades que a educação escolar contém. Ele recusará que este dever imposto pelo Estado seja exclusivo deste e se pronunciará a favor de que, além do Estado, outros entes também racionais, possam se desobrigar, concorrentemente, desse dever. O movimento não contesta que o Estado ofereça a educação escolar. Apenas não o quer como única opção, ainda que a legislação preveja a existência autorizada de escolas privadas.

É neste sentido que, com base na Declaração de 1948, o movimento afirmará que o cumprimento do dever em vista do direito à educação tem na família um antecedente mais fundamental do que o Estado. E é aqui que se pode trazer à tona o jusnaturalismo, tanto em sua vertente medieva, quanto em sua vertente moderna.

A vertente medieva considerava a natureza como produto da própria criação divina e abrange aquilo que não dependia da força criadora do ser humano. Como diz Bobbio (1997),

\footnotetext{
5 on peut prouver qu'une norme positive (ou bien une norme que l'on veut rendre positive), est juste, uniquement grâce à une démonstration à partir de principes universellement valables, dont le caractère obligatoire est autoévident. Les principes sont évidents parce qu'ils découlent de la nature qui, par définition, est ce qui est, et ne peut ni être objet d'un choix, d'une prise de position évaluative, ni le produit de la volonté et des actions des hommes.
} 


\section{pro.posições}

e o direito natural torna-se, então, ora a lei inscrita por Deus no coração dos homens - por Deus, não pelo príncipe ou pelos juízes ou pela assembleia popular -, ora a lei revelada pelos textos sagrados, que transmitem a palavra divina, ora, ainda, a lei comunicada aos homens por Deus, por meio da razão. (p. 31)

Veja-se, por exemplo, uma posição a este respeito advinda da Encíclica Divini Illius Magistri de Pio XI (1929):

A educação é obra necessariamente social e não singular. Ora, são três as sociedades necessárias, distintas e também unidas harmonicamente por Deus, no meio das quais nasce o homem: duas sociedades de ordem natural, que são a família e a sociedade civil; a terceira, a Igreja, de ordem sobrenatural. Primeiramente a família, instituída imediatamente por Deus para o seu fim próprio que é a procriação e a educação da prole, a qual por isso tem a prioridade de natureza, e, portanto, uma prioridade de direitos relativamente à sociedade civil. Não obstante, a família é uma sociedade imperfeita, porque não possui em si todos os meios para o próprio aperfeiçoamento, ao passo que a sociedade civil é uma sociedade perfeita, tendo em si todos os meios para o próprio fim que é o bem comum temporal, pelo que, sob este aspecto, isto é, em ordem ao bem comum, ela tem a preeminência sobre a família que atinge precisamente na sociedade civil a sua conveniente perfeição temporal.

A terceira sociedade em que nasce o homem, mediante o Baptismo, para a vida divina da graça, é a Igreja, sociedade de ordem sobrenatural e universal, sociedade perfeita, porque reúne em si todos os meios para o seu fim que é a salvação eterna dos homens, e, portanto, suprema na sua ordem

Por consequência, a educação que considera todo o homem individual e socialmente, na ordem da natureza e da graça, pertence a estas três sociedades necessárias, em proporção diversa e correspondente, segundo a actual ordem de providência estabelecida por Deus, à coordenação do seus respectivos fins.

Entre os defensores de que há um direito da lei divina ou da natureza, há a defesa de uma hierarquia deles diante do direito positivo. E, nesse sentido, o direito positivo não pode ser antinômico aos preceitos do direito natural. Este último precede o direito positivo e lhe dá fundamento. Em outros termos, o direito positivo deve respeitar o direito natural ou expressálo em sua conformidade.

Já pela vertente saída da Modernidade, em que a fé ou a religião vai se deslocando para o âmbito do privado, ao invés da tríade Deus, Sujeito, Objeto, fica-se com a díade Sujeito, Objeto. Nesse caso, o fundamento da realidade, portanto da natura (natureza como objeto), teria que ser outro. 


\section{pro.posıções}

$e$-ISSN 1980-6248

Nos primórdios da Idade Moderna, sob uma concepção antropológica antropocêntrica, o ser humano será visto como um conhecedor racional que pode explorar a ordem racional do universo, movido por leis próprias da ordem universal. Como diz Abbagnano (1970): "Para o jusnaturalismo moderno, o direito natural cessa de ser o caminho através do qual as comunidades humanas podem participar da ordem cósmica, ou contribuir com ela, para tornar-se uma técnica racional da coexistência” (p. 200). A razão humana será, então, o móvel de um racionalismo que buscará ordenar as relações sociais e propiciar o domínio da natureza, cada vez mais dessacralizada.

Essa concepção vai, então, ser recoberta pela dominância do fazer humano na vida social, com bases nas teses do contratualismo, em especial pela presença do Estado. Pode haver dois direitos, o natural e o civil, mas o segundo é mais amplo do que o primeiro.

Fora do Estado - dizia Hobbes - é o domínio das paixões. Logo, no Estado está a segurança. Ao contrário, diria a Igreja: fora da Igreja não há salvação. E a salvação que o Estado garante se perde se ele não reconhece e não se reconcilia com a fé.

Assim, a concepção leiga de Estado é mais do que a origem terrena do poder; é sobretudo a concepção de uma justiça terrena que em si produz segurança, paz.

A racionalização do Estado procede pari passu com a convicção de que o Estado é a forma mais alta ou menos imperfeita de convivência humana, e só no Estado o homem pode conduzir uma vida em conformidade com a razão. (Bobbio, 1989, p. 41)

Ou diretamente de Hobbes (1993):

As leis da natureza proíbem o furto, o homicídio, o adultério e todas as várias espécies de crimes. No entanto, é preciso determinar, por meio da lei civil, e não da lei natural, o que se deve entender por furto, homicídio, adultério, crime. Com efeito, nem toda subtração de algo possuído por outrem é furto, mas somente daquilo que é de sua propriedade. Portanto, determinar o que é nosso e o que pertence a outrem é algo que depende da lei civil. (p. 109)

Esta concepção atingirá seu auge com as teses baseadas em Hegel no Espírito Objetivo, as quais contestarão o modo como os jusnaturalistas entenderam o Estado. Conforme analisam Bobbio e Bovero (1986),

a idéia do Estado-razão chega até Hegel, que define o Estado como "o racional em-si e parasi" [ênfase no original]. Mas Hegel é também o crítico mais impiedoso do jusnaturalismo: a razão de que ele fala quando, desde o início da Filosofia do Direito, anuncia querer 


\section{pro.posições}

$e$-ISSN 1980-6248

compreender o Estado como uma coisa racional em si não tem nada a ver com a razão dos jusnaturalistas ... os jusnaturalistas imaginaram a sociedade civil como uma associação voluntária de indivíduos, enquanto o Estado é a unidade orgânica de um povo. (pp. 96-97)

Nesse sentido, para Hegel, cabe ao Estado solucionar os conflitos que nascem do individualismo possessivo. E a lei civil, trazida pelo Estado, impõe a obrigatoriedade escolar como meio de educabilidade das pessoas e, no caso do Brasil, salvo legislação em contrário, em instituições escolares autorizadas.

Ora, esses conflitos, próprios da sociedade de classes, forçaram uma retomada do jusnaturalismo em tempos mais recentes com base na justiça. Tome-se como base a complexidade do tema tratado por Bobbio (1997) na longa introdução que esse autor faz ao pensamento de Locke. ${ }^{6}$ Esse renascimento, segundo o pensador italiano, deve ser visto à luz de uma importante distinção nele contida: a teoria jusnaturalista propriamente dita e a exigência ética expressa por essa teoria.

O atual renascimento do jusnaturalismo [é] o ressurgimento da eterna exigência da ideia de justiça - que transcende continuamente o direito positivo e nos induz a tomar posição frente a ele para modificá-lo, aperfeiçoá-lo, adaptá-lo a novas necessidades e a novos valores... o direito natural não é um sistema de regras universais, válidas para todo o tempo e todos os lugares, mas um conjunto de princípios bastante genéricos e flexíveis que deve adaptar-se continuamente ao progresso histórico. (p. 25)

De algum modo, o que se depreende dos vários argumentos aduzidos pelo movimento da homeschooling é que a exclusividade do Estado, impondo que só possa haver educação escolar nas escolas públicas e nas escolas privadas autorizadas, é legal, mas não é justa.

E é essa tensão entre a lei positiva, que obriga os cidadãos a respeitá-la, e a exigência maior de justiça que o movimento também vai aduzir, apoiando-se na avaliação e na adaptação das leis positivas, de sorte que o direito da família não possa ser integralmente absorvido pela forma estatal do direito à educação, prevista pela legislação brasileira. Resulta daí que os direitos elaborados pela legislação estatal, derivados de convenção, não podem contraditar os valores apontados pela justiça que questionou determinadas formas assumidas por Estados, em especial em torno da Segunda Guerra.

\footnotetext{
${ }^{6}$ Não se pode, aqui senão indicar a importância da leitura deste livro, especialmente suas primeiras 73 páginas, pela sua riqueza histórica e conceitual.
} 


\title{
pro.posições
}

$e$-ISSN 1980-6248

Com efeito, os tempos contemporâneos, conhecedores de Estados que atingiram as raias do totalitarismo, fizeram com que houvesse uma limitação desse poder com relação a determinados bens pelo constitucionalismo e pelos direitos humanos. Como ainda afirma Bobbio (1997),

\begin{abstract}
a história da formação do Estado moderno é, em grande parte, a história das tentativas de tornar efetiva, por meio de vários dispositivos constitucionais, a exigência das teorias jusnaturalistas, manifestada durante alguns séculos, em favor de uma limitação do poder soberano. Passou-se, do controle do poder executivo por parte do legislativo, ao controle do legislativo por parte do poder constituinte. Encontramo-nos, agora, na fase da tendência irresistível no sentido do controle de uma ordenação jurídica parcial - o Estado - por uma ordem universal - a comunidade internacional. (p. 70)
\end{abstract}

Por sua vez, a Modernidade trará a figura do indivíduo como dotada de capacidade de fazer escolhas, resultando daí a sua liberdade de opção de caminhos para sua participação na vida social. Exsurge, então, o argumento da liberdade contra uma suposta opressão da obrigatoriedade, seja por considerá-la como tal, seja por entender que a norma legal não é um mandamento vinculante e, sim, uma diretriz autorizativa. E dessa liberdade pode a família aproveitar-se para atender aos ditames da educação, sem que tal se dê nos dispositivos da obrigatoriedade. Pode-se levantar a hipótese de que os defensores da homeschooling sejam, consciente ou inconscientemente, adeptos da teoria da "desobediência civil" de Thoreau (2001).

O que se pode deduzir, a partir de argumentos vários propostos pelo movimento da homeschooling, é que eles oscilam entre dois jusnaturalismos. De um lado, aquele que toma a família como precedente ao Estado e assim superior ao direito positivo estabelecido pelo Estado. E, de outro lado, os que propugnam pela liberdade de ensino entendida não só como a possibilidade de escolas privadas autorizadas, mas também como o direito do indivíduo de buscar caminhos próprios e alternativos, com apoio da família, dado que a educação é um direito.

No caso de se trazer o direito da família, a autoridade dos pais, ex generatione ou ex natura, na educação dos filhos, própria da união entre cônjuges (consociatio domestica), é fundamental para o desenvolvimento da formação biopsicológica da infância e da adolescência. O que exige cuidados, para que sejam respeitados, com suas características, nestes ciclos específicos da existência humana e possam, quando adultos, ser partícipes da 


\section{pro.posições}

$e$-ISSN 1980-6248

consociatio politica. É isso que promana do Capítulo VII do Título VIII da Constituição (Constituição BR, 1988), cujo artigo 227, ordena:

É dever da família, da sociedade e do Estado assegurar à criança e ao adolescente, com absoluta prioridade, o direito à vida, à saúde, à alimentação, à educação, ao lazer, à profissionalização, à cultura, à dignidade, ai respeito, à liberdade e à convivência familiar e comunitária, além de colocá-los a salvo de toda a forma de negligência, discriminação, exploração, violência, crueldade e opressão.

A educação que a família propicia se encaixa no artigo 1o da Lei de Diretrizes e Bases (Lei BR, 1996), artigo de larga amplitude.

Contudo, desde o final do século XIX, já se apontava a limitação dessa educação diante da complexificação da sociedade. Novas funções, novas instituições próprias da urbanização, estabelecem, pois, uma dialética entre a socialização familiar e a socialização escolar.

E é aí que se aninha a especificidade do direito à educação escolar e do dever do Estado de oferecê-lo e dos pais ou responsáveis de matricular seus filhos ou pupilos nos sistemas de educação formal. Para tanto é que a LDB (Lei BR, 1996) estabelece em seu art. 1o, \10: "Esta Lei disciplina a educação escolar, que se desenvolve, predominantemente, por meio do ensino, em instituições próprias".

\section{Conclusão}

As famílias têm a obrigação, sob pena de negligência, de matricular seus filhos nas instituições escolares de modo a superarem, desde cedo, um egocentrismo próprio da infância. A convivência escolar é mais do que um convite à superação desse egocentrismo, é um espaço privilegiado para que se estabeleçam com os outros relações maduras de reciprocidade e de reconhecimento do outro como igual e diferente.

Nesse sentido, cabe o pensamento de Kant, postulando a autonomia do sujeito e a ideia de a pessoa é sempre um fim, jamais podendo ser tomada como um meio. Essa autonomia do sujeito se dá no jogo da alteridade autonômica do outro. E a escola vem se 


\section{pro.posıções}

$e$-ISSN 1980-6248

tornando um dos últimos lugares onde acontece a convivência entre iguais e diferentes de modo sistemático, permanente e presencial.

Junto, pois, com a transmissão de conhecimentos importantes e imprescindíveis para a vida social, a educação escolar obrigatória visa à formação para a cidadania. Formação que convida ao respeito de valores, seja pelo conhecimento dos fundamentos da cidadania, seja pela vivência desses valores na convivência que a escola proporciona. A socialização institucional que a educação escolar propicia se volta para a superação do egocentrismo na dimensão do respeito mútuo e da reciprocidade. A formação para a cidadania só ocorre quando a pessoa se vê confrontada por situações em que o respeito de seus direitos se põe perante o respeito pelo direito dos outros. E os espaços da educação escolar, mercê das grandes transformações pelas quais nossas metrópoles passam, vêm se tornando, quiçá, um dos últimos redutos de uma socialização permanente e sistemática.

A escola é um lugar de convívio com o Outro: o negro, o pardo, o não crente, o pobre, o diferente, enfim. É um lugar institucional para se respeitar o outro, meu igual. Tal isolacionismo, posse de famílias bem representadas na distribuição de renda, pode se valer de recursos próprios e, com isso, sair-se bem nas provas. Mas os seus filhos escapam da possibilidade de pôr em situação de compartilhamento os seus recursos desenvolvidos em casa, em situação de compartilhamento.

Um processo de educação escolar limitado ao âmbito familiar corre o risco de reduzir o campo de um pertencimento social mais amplo e de se pautar por um exclusivismo que pode significar uma forma elitista e seletiva de segregação. Isso não retira a crítica que este movimento faz aos resultados ruins nas avaliações das redes escolares e a outros fenômenos que as pesquisas registram, como violência, bullying, entre outros. Serve como um alerta para que os poderes públicos se empenhem na solução mais ampla desses problemas, em especial na valorização docente e na oferta de sólida formação inicial.

É compreensível que, dada a cultura tradicional existente, dada a clareza existente sobre o assunto antes da Constituição de 1988, dado o caráter genérico de determinadas Declarações Internacionais das quais o Brasil tenha sido signatário, haja famílias pleiteando a possibilidade de educação escolar doméstica.

Esta tensão entre igualdade e liberdade foi trabalhada por Bobbio e Bovero (1986): 


\section{pro.posições \\ $e$-ISSN 1980-6248}

O problema mais difícil para uma teoria racional (ou que pretende ser racional) do Estado é o de conciliar dois bens a que ninguém está disposto a renunciar e que são (como todos os bens últimos) incompatíveis: a obediência e a liberdade. (p. 83)

Por isso, é preciso explicitar, justificar as razões dessa obrigatoriedade e insistir na importância do ensino obrigatório na faixa etária prevista em lei, com a devida presença dos alunos em instituições próprias de ensino presencial. Uma cultura relativa à obrigatoriedade deve ser explicada com base em valores calcados na dignidade do educando, na importância do dever do Estado e na busca da autonomia e da afirmação de uma cidadania solidária e participante da vida sociopolítica. 


\section{pro.posıções}

$e$-ISSN 1980-6248

\section{Referências}

Abbagnano, N. (1970). Dicionário de Filosofia. São Paulo: Mestre Jou.

Barbosa, L. M. R. (2013). Princípios, fundamentos e normatização do ensino em casa: contribuições para a análise da educação compulsória no Brasil. Tese de Doutorado, FEUSP, São Paulo, SP, Brasil.

Bobbio, N. (1987, dezembro). Reformismo, socialismo e igualdade. Revista Novos Estudos Cebrap, 19, 12-25.

Bobbio, N. (1989). Estudos sobre Hegel. São Paulo: UNESP: Brasiliense.

Bobbio, N. (1995). Direita e esquerda: razões e significados de uma distinção política. São Paulo: UNESP.

Bobbio, N. (1997). Locke e o direito natural. Brasília: Editora UNB.

Bobbio, N., \& Bovero, M. (1986). Sociedade e Estado na filosofia politica moderna. São Paulo: Brasiliense.

Boudens, E. (2001). Homeschooling no Brasil [Mimeo]. Brasília: Consultoria Legislativa/Câmara dos Deputados.

Boudens, E. (2002). Ensino em casa no Brasil [Mimeo]. Brasília: Consultoria Legislativa/Câmara dos Deputados.

Chartier, A.- M. (2013). Paradoxos da obrigatoriedade escolar. In D. G. Vidal, E. F. Sá, \& V. L .G. Silva (Orgs.), Obrigatoriedade escolar no Brasil (pp.412-438). Cuiabá: EDUFMT.

Cury, C. R. J. (2006). Educação escolar e educação no lar: espaços de uma polêmica. Educação e Sociedade, 27, 667-688.

Cury, C. R. J. (2009). Instruction au sein de la famille versus instruction au sein de l'ecole. Cabiers de la Recherche sur l'éducation et les savoirs, 8, 117-135.

Cury, C. R. J. (2013). Educação escolar e educação no lar (bomeschooling). In D. G. Vidal, E. F. Sá, \& V. L. G. Silva (Orgs.), Obrigatoriedade escolar no Brasil (pp.359-380). Cuiabá: EDUFMT. 


\section{pro.posıções \\ $e$-ISSN 1980-6248}

Gratien, L. (1993). Droit naturel. In A.J.Arnaud et al (Eds.), Dictionnaire encyclopédique de théorie et de sociologie du droit (pp.198-200). Paris: Librairie Générale de Droit et de Jurisprudence.

Hobbes, T. (1993). De cive. Petrópolis: Vozes.

Horta, J. S. B. (2013). Direito à Educação, obrigatoriedade escolar e extensão da escolaridade. In D.G. Vidal, E.F. SÁ, \& V.L.G. Silva, Obrigatoriedade escolar no Brasil (pp.381-398). Cuiabá: EDUFMT, 2013.

Marshall, T. (1967). Cidadania, classe social e status. Rio de Janeiro: Zahar.

Pio XI. (1929). Divini Illius Magistri. Recuperado em 14 dezembro de 2015, de www2.vatican.va/content/pius-xi/pt/encyclicals/documents/hf_pxi_enc_31121929_divini-illius-magistri.html.

Thoreau, H. D. (2001). A desobediência civil. Porto Alegre: LPM.

Vasconcelos, M. C. C. (2004). A casa e seus mestres: a educação no Brasil de Oitocentos. Rio de Janeiro: Griphus.

Legislação

Constituição dos Estados Unidos do Brasil (1946). Rio de Janeiro: Assembleia Constituinte.

Constituição da República Federativa do Brasil de 1988 (1988). Brasília: Presidência da República. Casa Civil. Subchefia para Assuntos Jurídicos.

Decreto-Lei BR, n. 2.848, de 7 de dezembro de 1940. Presidência da República. Casa Civil. Subchefia para Assuntos Jurídicos.

Emenda Constitucional n559, de 11 de novembro de 2009. Brasília: Presidência da República. Casa Civil. Subchefia para Assuntos Jurídicos.

Lei BR, n. 4.024, de 20 de dezembro de 1961. Fixa as Diretrizes e Bases da Educação Nacional. Revogada pela lei $n^{\circ} 9.394$, exceto os artigos $6^{\circ}$ a $9^{\circ}$. Presidência da República. Casa Civil. Subchefia para Assuntos Jurídicos. 


\section{pro.posıções \\ $e$-ISSN 1980-6248}

Lei BR, n. 8.069, de 13 de julho de 1990. Dispõe sobre o Estatuto da Criança e do Adolescente e dá outras providências. Presidência da República. Casa Civil. Subchefia para Assuntos Jurídicos.

Lei BR n. 9.394, de 20 de dezembro de 1996. Estabelece as diretrizes e bases da educação nacional. Diário Oficial da União, 20 de dezembro de 1996. Brasília: Presidência da República. Casa Civil. Subchefia para Assuntos Jurídicos.

Submetido à avaliação em 07 de março de 2016; revisado em 03 de novembro de 2016; aceito para publicação em 21 de abril de 2017. 